\title{
PKC $\alpha$-Mediated Downregulation of RhoA Activity in Depolarized Vascular Smooth Muscle: Synergistic Vasorelaxant Effect of PKC $\alpha$ and ROCK Inhibition
}

\author{
María del Carmen González-Montelongo ${ }^{a, b} \quad$ Cristina Porras-González \\ Rafaela González-Montelongo ${ }^{a}$ Gonzalo Revilla-González ${ }^{a}$ María Dolores Pastora,c \\ Antonio Castellano ${ }^{a, b}$ Juan Ureña ${ }^{a, b}$ \\ alnstituto de Biomedicina de Sevilla (IBiS)/Hospital Universitario Virgen del Rocío/CSIC/ Departamento \\ de Fisiología Médica y Biofísica, Universidad de Sevilla, Sevilla, Spain, ${ }^{b} R e d$ de Investigación \\ Cardiovascular (RIC)/CIBERCV, Sevilla, Spain, cProteomics Service-Instituto de Biomedicina de Sevilla \\ (IBiS), Sevilla, Spain
}

\section{Key Words}

Protein kinase C (PKC) • Rho (Rho GTPase) • Vascular smooth muscle cells • Calcium channel • Cell signaling $\bullet$ Phorbol ester $\bullet$ Depolarization

\begin{abstract}
Background/Aims: Protein kinase C (PKC)- and RhoA/Rho-associated kinase (ROCK) play important roles in arterial sustained contraction. Although depolarization-elicited RhoA/ROCK activation is accepted, the role of PKC in depolarized vascular smooth muscle cells (VSMCs) is a subject of controversy. Our aim was to study the role of PKC in arterial contraction and its interaction with RhoA/ROCK. Methods: Mass spectrometry was used to identify the PKC isoenzymes. PKC $\alpha$ levels and RhoA activity were analyzed by western blot and G-LISA, respectively, and isometric force was measured in arterial rings. Results: In depolarized VSMCs RhoA and PKC $\alpha$ were translocated to the plasma membrane, where they colocalize and coimmunoprecipitate. Interestingly, depolarization-induced RhoA activation was downregulated by PKC $\alpha$, effect reverted by PKC $\alpha$ inhibition. Phorbol 12,13-dibutyrate $(P D B u)$ induced the translocation of PKC $\alpha$ to the plasma membrane, increased the level of RhoA in the cytosol and reduced RhoA/ROCK activity. These effects were reverted when PKC was inhibited. Pharmacological or siRNA inhibition of PKC $\alpha$ synergistically potentiated the vasorelaxant effect of RhoA/ROCK inhibition. Conclusion: The present study provides the first evidence that RhoA activity is downregulated by PKC $\alpha$ in depolarized and PDBu treated freshly isolated VSMCs and arteries, with an important physiological role on arterial contractility.
\end{abstract}

M. González-Montelongo and C. Porras-González contributed equally to this work.

\begin{tabular}{ll}
\hline Juan Ureña & Instituto de Biomedicina de Sevilla, Edificio IBiS. Campus Hospital Universitario \\
and Antonio Castellano & Virgen del Rocío, Avenida Manuel Siurot s/n, E-41013, Sevilla (Spain) \\
& Tel. (34)-955-923060, (34)-955-923059, E-Mail jurena@us.es; acastell@us.es
\end{tabular}




\section{Cellular Physiology Cell Physiol Biochem 2019;52:76-93

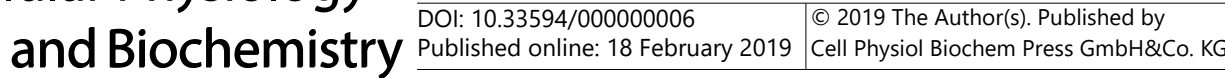 \\ González-Montelongo et al.: Functional Role of PKC $\alpha$-Induced RhoA Inhibition}

\section{Introduction}

Vascular smooth muscle cells (VSMCs) contraction is regulated by the cytosolic $\mathrm{Ca}^{2+}$ concentration and by the $\mathrm{Ca}^{2+}$ sensitivity of myofilaments: the former activates myosin light chain (MLC) kinase and the latter is achieved partly by inhibition of myosin light chain phosphatase (MLCP) and enhanced MLC phosphorylation [1, 2]. Such changes in $\mathrm{Ca}^{2+}$ sensitivity, that participate in the maintenance of arterial contraction, are now known to involve multiple cell signaling processes, including translocation of proteins from the cytosol to the plasma membrane and activation of kinases such as protein kinase C (PKC) and RhoA/ Rho-associated kinase (ROCK). In VSMCs $\mathrm{Ca}^{2+}$ and diacylglycerol (DAG)-dependent (PKC $\alpha$, $\mathrm{PKC} \beta$ and $\mathrm{PKC} \gamma$ ), $\mathrm{Ca}^{2+}$-independent (PKC $\varepsilon, \mathrm{PKC} \theta, \mathrm{PKC} \delta$ and $\left.\mathrm{PKC} \eta\right)$ and atypical (PKC 3 and $\mathrm{PKCl} / \lambda) \mathrm{PKC}$ isoenzymes have been described, although their physiological importance in vascular function is still subject of debate $[3,4]$. Rho family GTPases are key regulators in a wide range of physiological processes, including VSMCs contraction, cell motility, cell division, etc. [5]. A currently accepted model of $\mathrm{Ca}^{2+}$ sensitization includes inhibition of MLCP by RhoA/ROCK through the MLCP regulatory subunit (MYPT1) and PKC-potentiated inhibitory protein of 17-kDa (CPI-17) [6-8]. Both $\mathrm{Ca}^{2+}$ sensitization pathways not only work in parallel to inhibit MLCP, but they are also known to interact. For instance, RhoA can activate PKC $\alpha$ [9], while, on the other hand, PKC can inhibit or activate RhoA [10, 11]. In addition to GPCR activation, $\mathrm{Ca}^{2+}$ sensitization can be triggered by stimuli that cause membrane depolarization. High extracellular $\mathrm{K}^{+}(\mathrm{KCl})$, a depolarizing solution traditionally used to facilitate $\mathrm{Ca}^{2+}$ influx through L-type $\mathrm{Ca}^{2+}$ channels (LTCCs), can also activate $\mathrm{Ca}^{2+}$ sensitization and sustained contraction via the RhoA/ROCK pathway [12-16]. However, although depolarizationinduced RhoA/ROCK activation is widely accepted, whether $\mathrm{Ca}^{2+}$ sensitization can occur via $\mathrm{KCl}$-induced $\mathrm{PKC}$ activation remains unclear. Some reports have suggested that $\mathrm{KCl}$ does not cause PKC activation [17], whereas other studies have described that PKC can play a role in $\mathrm{Ca}^{2+}$ sensitization during depolarization [18]. As in some pathological situations VSMCs are depolarized and arterial contractility is increased [19-22], new studies should be addressed to test the role of PKC in depolarized VSMCs, as well as to identify possible new crosstalk between PKC and RhoA/ROCK. In this regard, previous studies in our laboratory have suggested that LTCCs are involved in the maintenance of arterial contraction via the metabotropic release of $\mathrm{Ca}^{2+}$ from internal stores and RhoA/ROCK activation [15, 23]. Since the $\mathrm{G}$ protein/phospholipase $\mathrm{C}$ cascade can also produce $\mathrm{DAG}$, an endogenous $\mathrm{PKC}$ activator, in this work we have examined the role of this protein on depolarization- or phorbol esterinduced sustained arterial contraction and the interaction between PKC and RhoA/ROCK $\mathrm{Ca}^{2+}$ sensitization pathways. We report an unknown $\mathrm{PKC} \alpha$-dependent RhoA/ROCK regulatory mechanism with an important physiological role on arterial contractility.

\section{Materials and Methods}

\section{Animals and Ethical Approval}

Male wistar rats (250-300 g) were killed with an overdose of sodium thiopental according to the DIRECTIVE 2010/63/EU regarding the use of animals for experimental and other scientific purposes (Royal Decree 53/2013, of February 8th). Experimental procedures were approved by the Department of Animal Production and Experimentation of the Instituto de Biomedicina de Sevilla/Hospital Universitario Virgen del Rocío.

\section{Tension Measurements}

Arterial contractility was performed as previously described [15]. In some experiments endothelial cells were removed by gently rubbing off the intimal surface with cotton-covered wire. The absence of functional endothelium was assessed by determining the lack of effect of acetylcholine $(0.5 \mu \mathrm{M})$ to induce relaxation in endothelin-I (10 $\mathrm{nM})$ pre-contracted arteries. 


\section{Cellular Physiology Cell Physiol Biochem 2019;52:76-93 \\ \begin{tabular}{ll|l}
\cline { 2 - 3 } DOI: 10.33594/000000006 & (c) 2019 The Author(s). Published by
\end{tabular} \\ and Biochemistry Published online: 18 February 2019 Cell Physiol Biochem Press GmbH\&Co. KG \\ González-Montelongo et al.: Functional Role of PKC $\alpha$-Induced RhoA Inhibition}

\section{Preparation of Cytosolic and Membrane or Total Fractions and Western Blot Analysis}

Given that measurement of proteins in the cytosolic and membrane fractions requires a relatively large amount of tissue, we performed these experiments using aorta and femoral arteries. Immediately after application of the different treatments, arterial rings were immersed in liquid nitrogen and then homogenized in lysis buffer ( $10 \mathrm{mM}$ Tris- $\mathrm{HCl}, 250 \mathrm{mM}$ sucrose, $2 \mathrm{mM}$ EDTA, $1 \mathrm{mM}$ DTT, $5 \mathrm{mM} \mathrm{MgCl}, 10 \mu \mathrm{L} / \mathrm{mL} \mathrm{Na}_{3} \mathrm{VO}_{4}, 10$ $\mu \mathrm{L} / \mathrm{mL}$ protease inhibitor cocktail, $10 \mu \mathrm{L} / \mathrm{mL}$ phenylmethylsulfonylfluoride (PMSF), $\mathrm{pH}$ 7.4) using a Sample Grinding Kit (GE Healthcare). Samples were centrifuged at $16,000 \mathrm{Xg}$ for $15 \mathrm{~min}$ at $4^{\circ} \mathrm{C}$. This procedure was repeated two or three times until a clarification of the supernatant was obtained. Finally, the supernatant was ultracentrifuged at $100,000 \mathrm{Xg}$ for $60 \mathrm{~min}$ at $4^{\circ} \mathrm{C}$. The supernatant of the ultracentrifugation, containing the cytosolic fraction, was collected and stored frozen until final analysis. To obtain the membrane fraction, the pellet obtained in the ultracentrifugation was washed in membrane lysis buffer ( $50 \mathrm{mM}$ HEPES, 50 $\mathrm{mM} \mathrm{NaCl}, 1 \mathrm{mM} \mathrm{MgCl}{ }_{2}, 2 \mathrm{mM}$ EDTA, $1 \mathrm{mM}$ PMSF, $10 \mathrm{mM} \mathrm{NaF}, 1 \mathrm{mM}$ DTT, $500 \mu \mathrm{M} \mathrm{Na}_{3} \mathrm{VO}_{4}$, and $10 \mu \mathrm{L} / \mathrm{mL}$ protease inhibitors, $\mathrm{pH}$ 7.5), and then ultracentrifuged at $120,000 \mathrm{Xg}$ for $50 \mathrm{~min}$ at $4^{\circ} \mathrm{C}$. The final pellet was resuspended in $20 \mu \mathrm{L}$ membrane lysis buffer in the presence of $1 \%$ Triton. To obtain total fractions, a protocol similar to that used for the cytosolic fraction was followed, except for the composition of the lysis buffer $(150 \mathrm{mM} \mathrm{NaCl}, 1 \mathrm{mM}$ PMSF, $0.026 \mathrm{mg} / \mathrm{mL}$ proteases inhibitors, $20 \mu \mathrm{L} / \mathrm{mL}$ phosphatase inhibitors, $1 \%$ Triton and $50 \mathrm{mM}$ Tris- $\mathrm{HCl}, \mathrm{pH} 7.5$ ), and centrifugation at 16,000 $\mathrm{Xg}$ for $10 \mathrm{~min}$. An aliquot of each protein extract was used for protein quantification by the Bradford Method. After addition of loading buffer (LB: 250 $\mathrm{mM}$ Tris, $4 \%$ SDS, $25 \%$ glycerol, $5 \%$-mercaptoethanol and $1 \mathrm{mg} / \mathrm{mL}$ bromophenol blue), samples were boiled at $95^{\circ} \mathrm{C}$ for $5 \mathrm{~min}$. Equal amounts of protein were loaded, electrophoresed on 8-12\% SDS-PAGE, and transferred to Hybond-P membranes (GE Healthcare). Immunodetection on the western blots was carried out first by membrane preincubation in $5 \%$ blotting-grade blocker (nonfat dry milk) in phosphate-buffered saline (PBS: $137 \mathrm{mM} \mathrm{NaCl}, 2.68 \mathrm{mM} \mathrm{KCl}, 4.02 \mathrm{mM} \mathrm{Na}_{2} \mathrm{HPO}_{4}, 1.76 \mathrm{mM} \mathrm{KH}_{2} \mathrm{PO}_{4}$ ) with $0.5 \%$ Tween 20 (PBS-T), at room temperature or in 5\% BSA in Tris-buffered saline (TBS: $100 \mathrm{mM}$ Tris and $1.5 \mathrm{M} \mathrm{NaCl}$ ) with $0.01 \%$ Tween 20 (TBS-T) at $4^{\circ} \mathrm{C}$ overnight to study phosphorylated residues (p-MYPT1). Membranes were then incubated with specific monoclonal anti-PKC $\alpha$ (diluted 1:1,000; BD Biosciences), monoclonal anti-RhoA (26C4) (diluted 1:250; Santa Cruz Biotechnology), polyclonal anti-MYPT1 (diluted 1:1,000; Merck) or polyclonal anti-phospho-MYPT1 (Thr850) antibody (diluted 1:500; Merck) and monoclonal anti- $\alpha$ tubulin antibody (diluted 1:10,000; Sigma-Aldrich) in $0.5 \%$ nonfat dry milk blotting solution overnight at $4^{\circ} \mathrm{C}$ or with $0.5 \%$ BSA in $0.01 \%$ TBS-T solution for phosphorylation studies, with gentle agitation. Following incubation, membranes were washed three times $(4,6$ and $8 \mathrm{~min}$ each) in PBS-T or TBS-T, and incubated for $1 \mathrm{~h}$ at room temperature in nonfat dry milk solution with HRP-linked secondary anti-mouse antibody (diluted 1:10,000; GE Healthcare) or anti-rabbit antibody (diluted 1:2,000; Thermo Scientific). After washing six times in PBS-T or TBS-T $(4,6,8,10,12$ and 20 min each), immunoreactive bands were visualized using the Enhanced Chemiluminescence Kit (GE Healthcare). The immunoreactive bands were analyzed using an ImageQuant LAS 4000 mini imaging densitometer (GE Healthcare) by quantifying relative band intensities after subtraction of local background in the vicinity of the bands. The density of each band was evaluated with Molecular Analyst software. $\alpha$-tubulin was used as loading control and values were normalized to the signals obtained with control tissues. The percentage of MYPT1 phosphorylation (expressed as percentage of total MYPT1) was calculated from densitometric values of MYPT1 P as MYPT1 phosphorylation $(\%)=$ ((MYPT1 P / Tubulin) / (total MYPT1 / Tubulin)) x 100.

\section{RhoA Activation Assay}

RhoA activity from femoral arterial rings was determined as previously described [15].

Cytosolic $\mathrm{Ca}^{2+}$ Measurements in Isolated VSMCs

Cytosolic $\left[\mathrm{Ca}^{2+}\right]$ measurements from dispersed VSMCs from femoral arteries were performed as previously described [15].

Immunocytochemistry and Confocal Microscopy

Immunocytochemical studies were performed as previously described [15]. 


\section{Cellular Physiology Cell Physiol Biochem 2019;52:76-93 \\ \begin{tabular}{l|l|l}
\hline DOI: $10.33594 / 000000006$ & 2019 The Author(s). Published by
\end{tabular} \\ and BiOChemistry Published online: 18 February 2019 Cell Physiol Biochem Press GmbH\&Co. KG \\ González-Montelongo et al.: Functional Role of PKC $\alpha$-Induced RhoA Inhibition}

\section{Immunoprecipitation Experiments}

Aorta and femoral arteries from four male rats were isolated as previously described, with some modifications. Arteries were incubated overnight at $4{ }^{\circ} \mathrm{C}$ and digested in $1 \mathrm{~mL}$ Hank's solution containing $0.1 \%$ (wt/vol) collagenase (Sigma Blend Collagenase Type F), 0.002\% (wt/vol) elastase (25 U/mg; CalbioChem) and $1 \mathrm{mg} / \mathrm{mL} \mathrm{BSA}$ at $37^{\circ} \mathrm{C}$ for $15 \mathrm{~min}$ (aorta) and $4 \mathrm{~min}$ (femoral). The partially digested tissue was washed twice with $1 \mathrm{~mL}$ of enzyme-free buffer solution. Tissue was then transferred into $4 \mathrm{~mL}$ of PSS (pH 7.4) containing (in mM): $140 \mathrm{NaCl}, 2.7 \mathrm{KCl}, 3.5 \mathrm{MgCl}_{2}, 10 \mathrm{HEPES}$ and 10 glucose, and gently dispersed to yield isolated VSMCs. Calcium was gradually added to a final concentration of $2.5 \mathrm{mM}$ during $30 \mathrm{~min}$, and $2 \mathrm{~mL}$ of dispersed cells were stimulated with $70 \mathrm{mM} \mathrm{KCl}$ for $10 \mathrm{~min}$. Both stimulated and unstimulated cells were centrifuged at $16,200 \mathrm{X} g$ for $1 \mathrm{~min}$ at $4^{\circ} \mathrm{C}$. Cells were disrupted in $25 \mu \mathrm{L}$ lysis buffer with 1\% Nonidet-P40 (in mM: $150 \mathrm{NaCl}, 1 \mathrm{PMSF}, 50$ Tris-HCl), $0.026 \mathrm{mg} / \mathrm{mL}$ proteases inhibitors, $50 \mu \mathrm{g} / \mathrm{mL}$ DNase, pH 7.5) and incubated in ice during $30 \mathrm{~min}$. The supernatant material was collected and the protein content determined by Bradford Method. Each sample (3-5 $\mu \mathrm{g} / \mu \mathrm{L}$ protein) was subjected to preclearing with $40 \mu \mathrm{L}$ (50\% concentration) of protein G-Sepharose beads equilibrated with Nonidet-P40 Cell Lysis Buffer (Invitrogen) rocked for $15 \mathrm{~min}$ and then collected by centrifugation at 2, $300 \mathrm{Xg}$ for $2 \mathrm{~min}$ at $4^{\circ} \mathrm{C}$. The supernatant was incubated with $5 \mu \mathrm{g}$ anti-RhoA antibody (rabbit polyclonal RhoA (119) S/C-179) and rocked overnight at $4^{\circ} \mathrm{C}$. Then $40 \mu \mathrm{L}(50 \%$ concentration) of protein G-Sepharose beads were added and rocked for $4 \mathrm{~h}$ at $4^{\circ} \mathrm{C}$. The beads with bound proteins were then collected by centrifugation at $3,100 \mathrm{Xg}$ for $3 \mathrm{~min}$ at $4^{\circ} \mathrm{C}$. Protein G-Sepharose were washed in wash buffer (in mM: $150 \mathrm{NaCl}$ and 50 Tris- $\mathrm{HCl}, \mathrm{pH} \mathrm{7.5)}$ three times and boiled in LB. Proteins from the immunoprecipitates were separated onto 8-15\% SDS-PAGE gel and transferred to a PVDF membrane. Immunoblotting was performed using mouse monoclonal 1:500 anti-PKC $\alpha$ antibody or 1:250 mouse monoclonal anti-RhoA antibody.

\section{Transfection of Arterial Rings}

siRNA molecules were intracellularly delivered using the Chariot Protein Delivery reagent (Active Motif). Femoral and aorta rings were incubated in DMEM for $1 \mathrm{~h}$ at $37^{\circ} \mathrm{C}$. For each transfection, $5 \mu \mathrm{L}$ de Chariot in $50 \mu \mathrm{L}$ deionized water were mixed with $3.2 \mu \mathrm{L}$ of siRNA molecules $(25 \mu \mathrm{M})$ in $50 \mu \mathrm{L}$ PBS and incubated at room temperature for $30 \mathrm{~min}$ to allow formation of the complexes. Arteries were transferred to a sterile 24-well cell culture plate, overlaid with $200 \mu \mathrm{L}$ of OPTIMEN, covered with $100 \mu \mathrm{L}$ of Chariot, gently mixed, and incubated for $1 \mathrm{~h}$ at $37^{\circ} \mathrm{C}$. Tissues were supplemented with $500 \mu \mathrm{L}$ DMEM for $2 \mathrm{~h}$ at $37^{\circ} \mathrm{C}$. Every $24 \mathrm{~h}$ the medium was changed. At $72 \mathrm{~h}$ arterial rings were mounted in the myograph and functional studies were performed. An in silico study of the siRNAs specificity was performed. siRhoA hybridizes only with RhoA (bases 256 (5') $\rightarrow 276$ (3') for antisense strand (taGCUGUCGGGACUAUCAAAU), and 258 (3') $\rightarrow 276$ (5') for sense strand (CGACAGCCCUGAUAGUUUAtt). Similarly, of the known PKC isozymes only the PKC $\alpha$ transcript hybridized with the siPKC $\alpha$ (bases 167 (5') $\rightarrow 187$ (3') for the antisense strand (gtGGACGCUGUACUUACAAGU), and 169 ( $3^{\prime}$ ) $\rightarrow 187$ ( $5^{\circ}$ ) for the sense strand (CCUGCGACAUGAAUGUUCAtt). All analyzed transcripts are from rat, and were extracted from IPA Ingenuity (IPA®, QIAGEN). In silico analysis was performed using SnapGene® Viewer 2.7.2. (GSL Biotech) [24].

\section{Identification of Proteins From Protein Extracts. In-solution Protein Digestion \\ In-solution digestion was performed as reported elsewhere [25].}

\section{$L C-M S / M S$}

Peptides were analyzed using EASYnano-LC 1000 on a Q Exactive Plus Orbitrap mass spectrometer (Thermo Scientific). Peptides were separated on a pre-column $75 \mu \mathrm{m}$ x $2 \mathrm{~cm}$, nanoViper, C18, $3 \mu \mathrm{m}, 100 \AA$ (Acclaim PepMap 100) and analytical column $50 \mu \mathrm{m}$ x $15 \mathrm{~cm}$, nanoViper, C18, $2 \mu \mathrm{m}, 100 \AA$ (Acclaim PepMap RSLC) at a flow rate of $200 \mathrm{~nL} / \mathrm{min}$. Water and ACN, both containing $0.1 \%$ formic acid, were used as solvents $A$ and B, respectively. The gradient was started and kept at $10 \%$ B for $5 \mathrm{~min}$, ramped to $60 \%$ B over 60 min or $120 \mathrm{~min}$, depending on the sample complexity, and kept at $90 \%$ B for another $5 \mathrm{~min}$. Operating in the datadependent mode to switch from full MS scan (mass width $200-1800 \mathrm{~m} / \mathrm{z}$ ). For data dependent analysis, the top 10 most abundant ions were analyzed for MS/MS analysis while +1 ions were excluded from MS/ MS analysis, with a normalized collision energy of 32\%. The raw data were searched with the Sequest HT node of Proteome Discoverer 1.4. The uniprot_ref_rat database (35, 702 protein entries), was utilized for the searches. Variable modifications of methionine oxidation and Carboxymethylation of cysteines were 


\section{Cellular Physiology Cell Physiol Biochem 2019;52:76-93 \\ \begin{tabular}{l|l|l}
\hline DOI: $10.33594 / 000000006$ & 2019 The Author(s). Published by
\end{tabular} \\ Published online: 18 February 2019 Cell Physiol Biochem Press GmbH\&Co. KG \\ González-Montelongo et al.: Functional Role of PKC $\alpha$-Induced RhoA Inhibition}

considered. All protein identification results were filtered to include only high confidence peptides with peptide mass deviation $<10 \mathrm{ppm}$, charge state $>2$ and a minimum of 2 unique peptides per protein. The mass tolerance of fragments ions was $<0.8 \mathrm{Da}$.

\section{Materials and Reagents}

GF-109203X (GFX), Chelerythrine (Chelery), HA-1077 dihydrochloride (fasudil), phorbol 12, 13-dibutyrate (PDBu), phorbol 12-myristate 13-acetate (PMA), Y27632, 4-Amino-3-(4-chlorophenyl)-1-(tbutyl)-1H-pyrazolo [3, 4-d]pyrimidine (PP2), DAPI dilactate, formalin solution, mouse monoclonal anti- $\alpha$ tubulin and salts were obtained from Sigma-Aldrich. U-46619 was obtained from Cayman Chemical. RhoA G-LISA was purchased from Cytoskeleton. Sample Grinding Kit, Hybond-P, ECL Western Blotting Analysis System and ECL mouse IgG HRP-linked whole Ab were obtained from GE Healthcare. The rabbit polyclonal anti-RhoA (119) antibody, raised against a peptide mapping within an internal domain of RhoA p21, mouse anti-RhoA (26C4), raised against an epitope corresponding to amino acids 120-150 of RhoA and the phosphatase inhibitors were purchased from Santa Cruz Biotechnology. The mouse anti-PKC $\alpha$ was from BD Biosciences. The anti-rabbit antibody was purchased from Thermo Scientific and anti-mouse was from GE Healthcare. Alexa Fluor 488 donkey anti-mouse IgG and Alexa Fluor 568 goat anti-rabbit IgG, that react with IgG heavy chains and all classes of immunoglobulin light chains from mouse and rabbit respectively, were purchased from Molecular Probes (Invitrogen). Protein levels of phosphorylated-MYPT1 and total MYPT1, were determined using polyclonal anti-p-MYPT1 (Thr850) (Merckmillipore, Cat \# 36-003) and anti-MYPT1 (Merckmillipore, Cat \#07-672) antibodies, respectively. Fluorescent Mounting Medium was from DAKO. The different siRNA for RhoA (siRhoA), PKC $\alpha$ (siPKC) and scramble (siRNA control) were obtained from Ambion (Life Technologies). Sequencing Grade Modified Trypsin was purchased from Promega. Acclaim PepMap®100, $75 \mu \mathrm{m}$ x 2 cm, nanViper C18, $3 \mu \mathrm{m}, 100 \AA ̊$ Precolumn and PepMap® RSLC C18, $2 \mu \mathrm{m}, 100 \AA$, $75 \mu \mathrm{m} \times 50 \mathrm{~cm}$ Column were purchased from Thermo Scientific. Oasis $®$ HLB $1 \mathrm{cc}(10 \mathrm{mg})$ and Oasis $®$ MCX 1 cc (30 mg) Extraction Cartridges were obtained from Oasis (Waters).

\section{Ingenuity Pathways Analysis (IPA)}

The functional and network analyses were generated through the use of QIAGEN's Ingenuity Pathway Analysis software [26] (IPA®, QIAGEN Redwood City, www.qiagen.com/ingenuity). The data set from the LC-MS/MS, which used Z-score for assessing the match of observed and predicted up/down regulation patterns. We found that a Z-score is particularly suited for this kind of problem since it serves as both a significance measure and a predictor for the activation state of the regulator. To create protein networks, the proteins were overlaid onto a global molecular network developed from information contained in the Ingenuity Knowledge Base.

\section{Data Analysis and Statistics}

Data are presented as mean \pm S.E.M. Differences between sample means were assessed by the one-way ANOVA followed by Tukey post hoc test when comparing three or more groups and two-tailed Student's $t$-test to compare two groups. We used non-parametrical statistical tests, Kruskal-Wallis test followed by Mann-Whitney $U$ test, where appropriate. Comparisons between experiments from the same animals were assessed by paired $t$ test. Dose-response curves were fitted to a logistic equation using nonlinear regression analysis tools provided in SigmaPlot software. Values of $\mathrm{P}<0.05$ were considered significant. Statistical analysis was performed with SPSS software.

\section{Results}

Depolarization-induced RhoA Activation is Regulated in a PKC $\alpha$-dependent Manner

To study the role of PKC in VSMCs contraction, we have treated arterial tissue with two stimuli: $70 \mathrm{mM}$ external $\mathrm{K}^{+}(70 \mathrm{~K})$ to depolarize membrane potential, and phorbol 12, 13-dibutyrate (PDBu) to activate PKC. Initially, we performed mass spectrometry experiments and IPA analysis (IPA®, QIAGEN) to identify the specific proteins signature for each stimulus in arterial tissue (Fig. 1A). PKC $\alpha$, PKC $\beta$ and PKC $\delta$ isoenzymes were

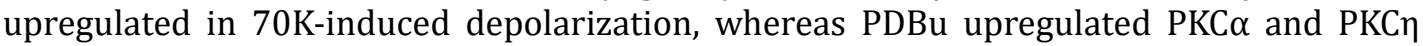



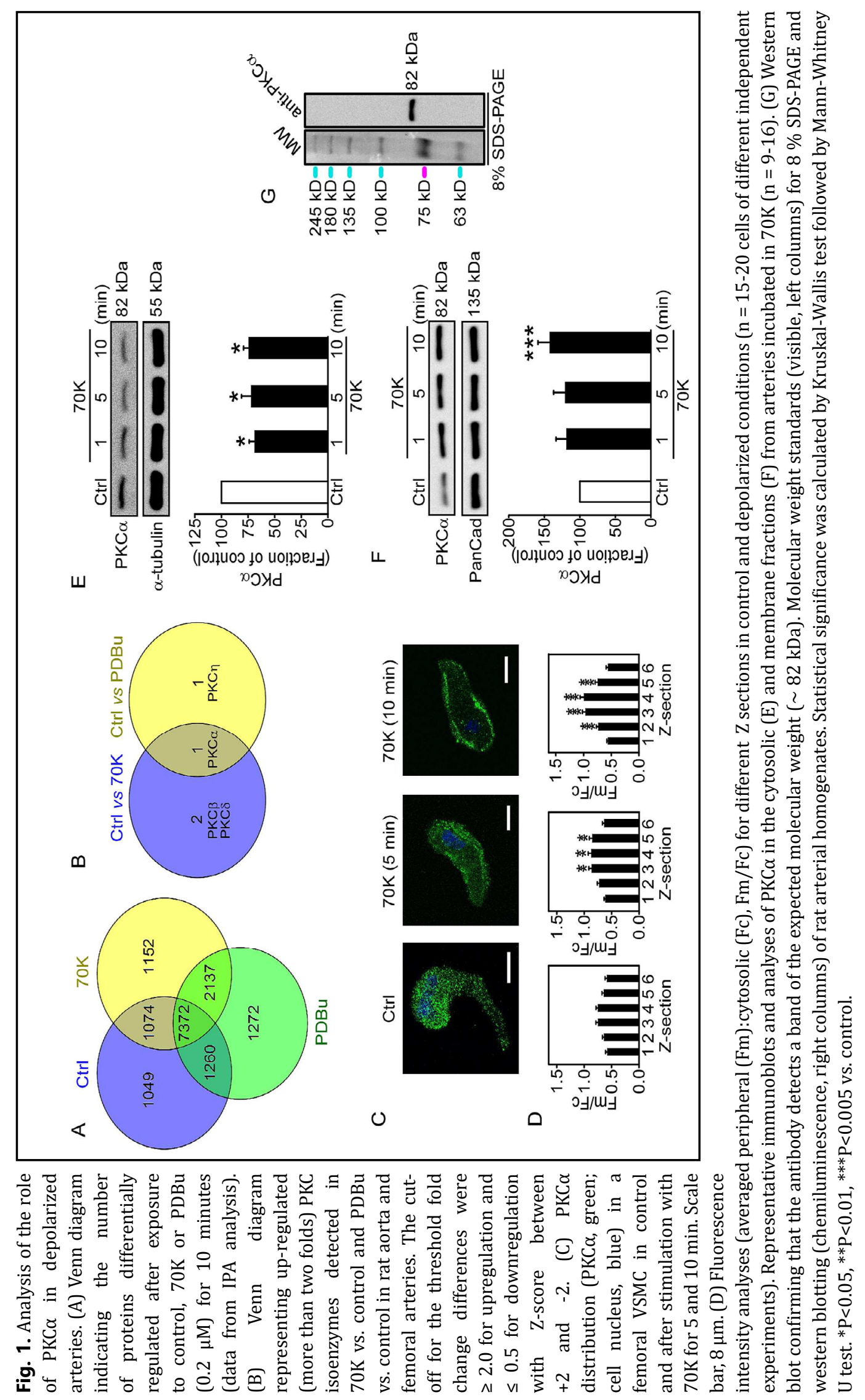
A
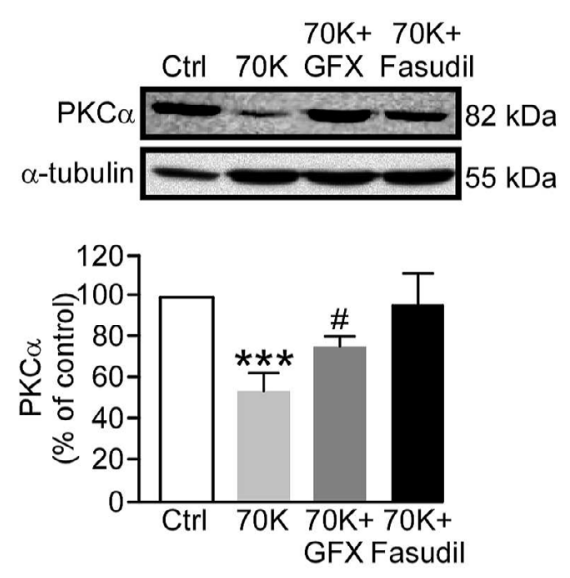

B
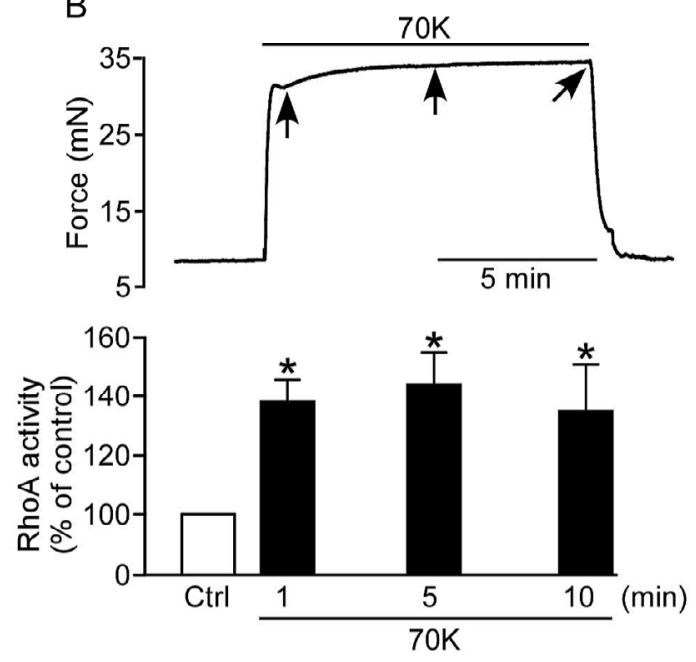

C

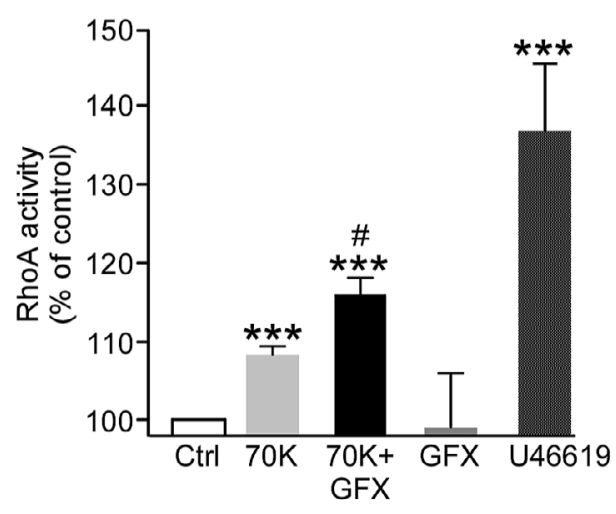

Fig. 2. Effect of $P K C \alpha$ inhibition on depolarization-induced RhoA activation. (A) Representative immunoblot (top) and analysis (bottom) illustrating the effects of PKC and ROCK inhibitors on PKC $\alpha$ protein levels in cytosolic extracts obtained from arterial rings bathed with $70 \mathrm{~K}$ for $10 \mathrm{~min}(\mathrm{n}=6)$. 70K-induced PKC $\alpha$ translocation was reverted with GFX $(0.5 \mu \mathrm{M})$ or fasudil $(1 \mu \mathrm{M})$. (B) Representative trace of 70K-evoked contraction (top) and statistical analysis of depolarization-induced RhoA activation (bottom). Arrows indicate the times at which arterial rings were frozen for posterior measurement of RhoA activity with the G-LISA test $(n=10)$. (C) RhoA activity in response to different stimuli. In the 70K+GFX samples, arteries were preincubated with GFX $(0.5 \mu \mathrm{M})$ for $30 \mathrm{~min}$, and then exposed to $70 \mathrm{~K}$ for $10 \mathrm{~min}$. U46619 (1 $\mu \mathrm{M})$ was used as positive control $(n=5)$. Statistical significance was calculated by one-way ANOVA or Kruskal-Wallis test followed by either Student-Newman-Keuls t-test, Tukey, or MannWhitney U test, where appropriate. ${ }^{*} \mathrm{P}<0.05,{ }^{* * *} \mathrm{P}<0.005$ vs. control; ${ }^{*} \mathrm{P}<0.05$ vs. $70 \mathrm{~K}$.

(Fig. 1B). As both stimuli activated PKC $\alpha$, an isoenzyme that is expressed in almost all blood vessels $[17,27]$, we studied its role in depolarization-induced arterial contraction. Since PKC activation involves translocation of the protein to its target site close to the cell membrane, we performed fluorescence immunocytochemistry studies on freshly isolated VSMCs from femoral arteries following stimulation with 70K. Depolarization for 5 and 10 min induced the translocation of PKC $\alpha$ to the periphery of the VSMCs (Fig. 1, C and D). These results were confirmed by western blot analysis, showing that in 70K-treated tissue there was a reduction of PKC $\alpha$ in the cytosolic fraction (Fig. 1E) with a concomitant increase in the membrane fraction (Fig. 1F). Given that these results were repetitive for the rest of the experiments we will only show PKC $\alpha$ in the cytosolic fraction. Fig. 1G shows western blot results confirming 


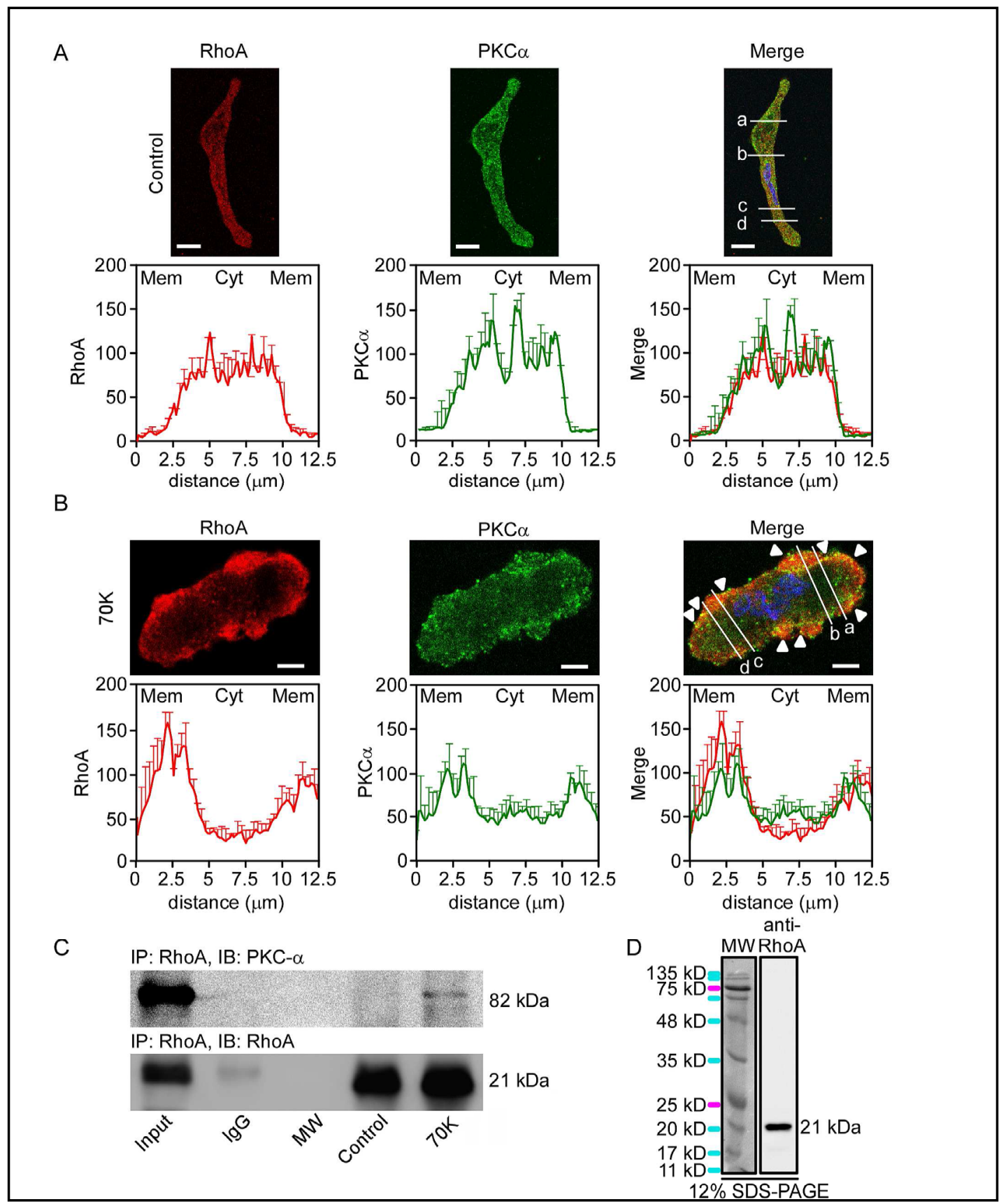

Fig. 3. Depolarization-induced RhoA and $\mathrm{PKC} \alpha$ translocation to the periphery of rat arteries and coimmunoprecipitation of both proteins. Confocal immunofluorescence images (top panels) and immunofluorescence analyses (bottom panels) illustrating PKC $\alpha$ and RhoA distribution (PKC $\alpha$, green; RhoA, red; cell nucleus, blue) in resting conditions (control, A) or 70K (B) in VSMCs from femoral arteries. Analyses were performed across four lines in different parts of the cell ( $a, b, c$ and $d$ in merged images). Scale bars represent $8 \mu \mathrm{m}(\mathrm{A})$ or $4 \mu \mathrm{m}(\mathrm{B}),(\mathrm{n}=3)$. Data represent mean \pm S.E.M. (C) Effect of depolarization on PKC $\alpha$ RhoA interaction from dispersed cells of femoral and aortic arterial tissue. Representative experiment that illustrates association of RhoA with PKC $\alpha(n=3)$. Immunoprecipitation was performed with an anti-RhoA antibody, and western blots using PKC $\alpha$ (top) or RhoA (bottom) antibodies. (D) Western blot confirming that the antibody detects a band of the expected molecular weight $(\sim 21 \mathrm{kDa})$. Molecular weight standards (visible, left columns) for $12 \%$ SDS-PAGE and western blotting (chemiluminescence, right columns) of rat arterial homogenates $(n=3)$. 
that the antibody detects a band of the expected molecular weight. The bisindolylmaleimide GF-109203X (GFX), a PKC inhibitor [28], significantly reversed the reduction of PKC $\alpha$ in the cytosolic fraction (Fig. 2A). We have used $0.5 \mu \mathrm{M}$ GFX because this value is close to the $\mathrm{IC}_{50}$ for GFX observed in contractions elicited by PDBu (see below) and it does not affect $70 \mathrm{~K}$-induced $\mathrm{Ca}^{2+}$ entry measured at $10 \mathrm{~min}$ in depolarized VSMCs $(\mathrm{R}(\mathrm{F} 340 / 380)=0.83$, $\mathrm{n}=27$ in $70 \mathrm{~K}$; $\mathrm{R}(\mathrm{F} 340 / 380)=0.89, \mathrm{n}=37$, in $70 \mathrm{~K}+\mathrm{GFX}$ ) (data not shown). HA-1077 dihydrochloride (fasudil, $1 \mu \mathrm{M}$ ), a ROCK inhibitor, suppressed 70K-induced PKC $\alpha$ activation (Fig. 2A), suggesting that ROCK is involved in $\mathrm{PKC} \alpha$ activation, as also occurs with some agonists [9]. Since ROCK is a downstream RhoA effector, we studied the role of RhoA in this regulatory pathway by measuring RhoA activity. As expected from our previous results $[15,16]$, exposure of arterial rings to $70 \mathrm{~K}$ induced an increase in RhoA activity (Fig. 2B). Interestingly, $0.5 \mu \mathrm{M}$ GFX, which did not significantly affected basal RhoA activity, markedly potentiated the effect of depolarization (Fig. 2C). An increase in the activity of RhoA was observed when arteries were treated with U46619, a thromboxane A2 analog that activates RhoA (Fig. 2C). As these results suggest that PKC $\alpha$ can negatively regulate RhoA activity, we hypothesized that depolarization could translocate both proteins toward the plasma membrane and facilitate their interaction.

We next examined in immunostained isolated VSMCs the cellular distribution of RhoA and PKC $\alpha$ under basal conditions and in response to depolarization. Fig. 3A (top panels) shows the distribution of RhoA and PKC $\alpha$ in an isolated VSMCs under resting conditions. The line graph analysis across four lines in different parts of the cell (a, b, c and d) shows that fluorescence intensity was almost uniform across the cytoplasm (Fig. 3A, bottom panels). Application of $70 \mathrm{~K}$ for 10 min caused VSMCs contraction and RhoA and PKC $\alpha$ translocation toward the periphery of the cell, reflecting the activation of both proteins (Fig. 3B, top panels). Accordingly, the line graph analysis reflected higher fluorescence intensity in the periphery than in the central cytosol (Fig. 3B, bottom panels), confirming the colocalization of PKC $\alpha$ and RhoA in the cell periphery in the 70K-treated VSMCs. To determine whether depolarization-induced regulation of RhoA by PKC $\alpha$ occurs as a result of their physical interaction, isolated VSMCs were stimulated with $70 \mathrm{~K}$ for $10 \mathrm{~min}$, and cell extracts were immunoprecipitated with a RhoA antibody. Western blot analyses using monoclonal antiPKC $\alpha$ or anti-RhoA antibodies show that stimulation with $70 \mathrm{~K}$ produces an increase in the association of RhoA with PKC $\alpha$ (Fig. 3C). Fig. 3D shows western blot results confirming that the antibody detects a band of the expected molecular weight. Taken together, these data demonstrate that depolarization activates RhoA and PKC $\alpha$ and recruits both proteins to the plasma membrane, where they interact, favoring RhoA inhibition by PKC $\alpha$.

Pharmacologic Inhibition or siRNA-mediated Silencing of RhoA/ROCK and PKC $\alpha$ Produces Synergistic Vasorelaxant Effects on Depolarization-induced Sustained Arterial Contraction

To study the physiological role of RhoA/ROCK regulation by PKC $\alpha$ we measured isometric force in arterial rings treated with PKC $\alpha$ and RhoA/ROCK inhibitors or siRNAs. Fig. 4A shows a representative trace illustrating the cumulative vasorelaxant effect of fasudil on femoral arterial rings precontracted with 70K. Unexpectedly, GFX, that had no effect on depolarization-induced contraction (Fig. 4B), markedly potentiated, in a synergistic and nonadditive manner, the vasorelaxant effect of fasudil $\left(\mathrm{IC}_{50}=7.36 \mu \mathrm{M}\right.$ for fasudil, $\mathrm{IC}_{50}=3.30 \mu \mathrm{M}$ for GFX+fasudil) (Fig. 4, C and D). As RhoA/ROCK also regulates signaling in endothelial cells [29], we performed experiments in endothelium-denuded femoral arterial rings. In these arteries, GFX $(0.5 \mu \mathrm{M})$ markedly potentiated the vasorelaxant effect of fasudil on sustained contraction, indicating that the endothelium is not involved in this phenomenon $\left(\mathrm{IC}_{50}=4.8\right.$ $\mu \mathrm{M}$ for fasudil, $\mathrm{n}=9$; $\mathrm{IC}_{50}=3.4 \mu \mathrm{M}$ for $\mathrm{GFX}+$ fasudil, $\mathrm{n}=6$ ) (data not shown). To eliminate nonspecific pharmacological effects of ROCK and PKC inhibitors, we transiently knocked-down RhoA and PKC $\alpha$ with specific and validated siRNAs (see Material and Methods). Consistent with the results obtained in the pharmacological approach, application of siRhoA significantly reduced $(\sim 17 \%)$ the sustained component of $70 \mathrm{~K}$-induced contraction (Fig. 4, E and H), when compared to a control siRNA (scramble), whereas siPKC $\alpha$ did not produce any significant 


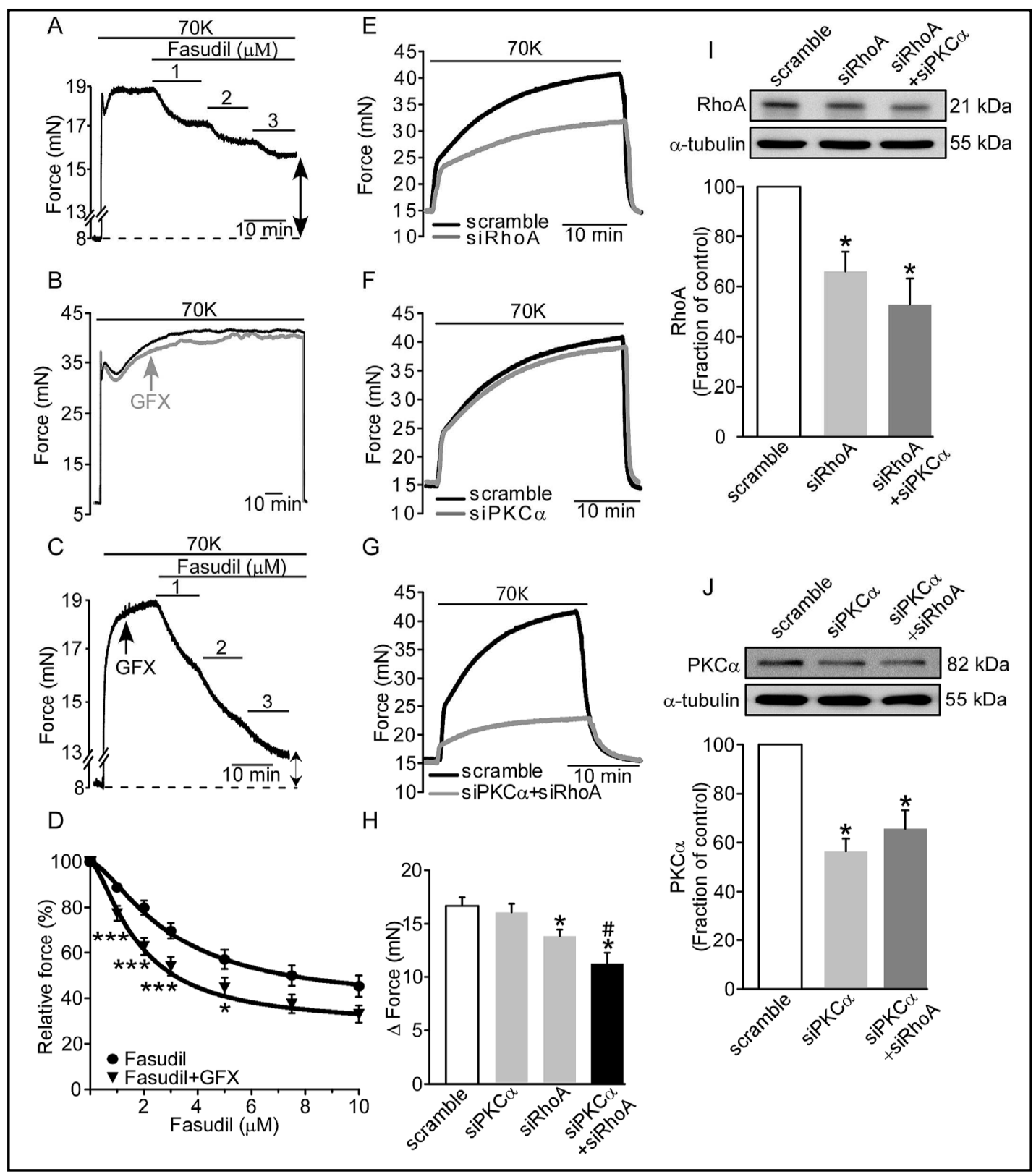

Fig. 4. Pharmacological inhibition or siRNA-mediated silencing of RhoA and PKC $\alpha$ induced synergistic vasorelaxant effects on depolarization-elicited sustained arterial contraction. Representative traces illustrating the effects of increasing doses of fasudil (A) or $0.5 \mu \mathrm{M}$ GFX (B) in depolarized (70K) arteries. (C) The vasorelaxant effect of fasudil was synergistically potentiated in the presence of GFX. Arrow indicates application of GFX. (D) Cumulative dose-response curves of fasudil in the absence ( $)$ or presence ( $\boldsymbol{\nabla}$ ) of GFX $(n=20)$. Dose-response curves were fitted to a logistic equation using nonlinear regression analysis tools provided in SigmaPlot software. Statistical significance was calculated by one-way ANOVA followed by Student-Newman-Keuls t-test. ${ }^{*} \mathrm{P}<0.05,{ }^{* * *} \mathrm{P}<0.005$ vs. control. (E-G) Representative traces to illustrate the effect of siRhoA (E) and siPKC $\alpha$ (F) or double siRNA (G) in depolarized arterial rings. (H) Statistical analysis showing the effects of the indicated siRNAs on isometric force, measured at $10 \mathrm{~min}(\mathrm{n}=12)$. Arteries were transfected for $72 \mathrm{~h}$ with the corresponding siRNAs. Statistical significance was calculated by one-way ANOVA followed by Student-Newman-Keuls t-test ${ }^{*} \mathrm{P}<0.05$ vs. scramble. ${ }^{\#} \mathrm{P}<0.05$ vs. siRhoA. (I-J) Representative western blots (top) and statistical analysis (bottom) showing the effects of siRhoA (I) and siPKC $\alpha(J)$ on protein levels $(n=12)$. Statistical significance was calculated by one-way ANOVA followed by paired t-test. ${ }^{*} \mathrm{P}<0.05$ vs. scramble. 
Fig. 5. Role of PKC and ROCK in $70 \mathrm{~K}$-induced contractions in rat basilar arterial rings. (A) Superimposed traces showing the effects of fasudil $(1 \mu \mathrm{M})$ alone or fasudil+chelerythrine $(5 \mu \mathrm{M})$ (gray) on the tonic component of the depolarization-induced contraction. (B) Representative trace showing the effect of PBDu $(0.05 \mu \mathrm{M})$ on the vasorelaxant effect of fasudil in 70K-induced contractions. (C) Quantitative summary of the effects of fasudil, fasudil + chelerytrine and fasudil + $\mathrm{PDBu}$ on the tonic component of the depolarization-induced contractions (fasudil, $\mathrm{n}=$ 21; fasudil + chelerytrine, $\mathrm{n}$ = 6; fasudil + PDBu, $\mathrm{n}=3$ ) . (D) Superimposed traces showing the isometric force developed in response to $70 \mathrm{~K}$ in the presence of the ROCK inhibitor Y27632 (1 $\mu \mathrm{M})$ alone or combined with GFX (0.5 $\mu \mathrm{M})$ (gray). (E) Quantitative summary of the effect of GFX and Y27632 on the sustained component of the depolarization-induced contractions (Y27632, $\mathrm{n}=3$; Y27632 + GFX, n =4). Statistical significance was calculated by Kruskal-Wallis test followed by Mann-Whitney $\mathrm{U}$ test. ${ }^{*} \mathrm{P}<0.05$ vs. $70 \mathrm{~K}$, ${ }^{\text {}} \mathrm{P}<0.05$ vs. fasudil for panel $\mathrm{C}$; ${ }^{*} \mathrm{P}<0.05$ vs. control, ${ }^{\text {}} \mathrm{P}<0.05$ vs. Y27632 for panel (E).

effect (Fig. 4, F and H). The vasorelaxant effect of siRhoA was significantly potentiated when PKC $\alpha$ was also silenced (33\% reduction) (Fig. 4, G and H). Thus, the siRNAs experiments confirmed the pharmacological results. On the other hand, siPKC $\alpha$ did not significantly affect RhoA expression and vice versa (Fig. 4, I and J). We also tested if arteries from different vascular territories, such as basilar artery, have the same pharmacological response. Fig. 5 shows qualitatively similar synergistic vasorelaxant effects in depolarized basilar arteries when ROCK and PKC were inhibited with fasudil and chelerythrine chloride, respectively (Fig. 5, A and C). Application of $0.05 \mu \mathrm{M}$ PDBu to depolarized arteries markedly reduced the vasorelaxant effect of fasudil $(1 \mu \mathrm{M})$ on the sustained component of depolarization-induced contraction, indicating that PKC activation decreases RhoA/ROCK activity (Fig. 5, B and C). Similar vasorelaxant effects were obtained when arterial rings were treated with Y27632 and GFX, ROCK and PKC inhibitors respectively (Fig. 5, D and E). Taken together, these data confirm that depolarization activates RhoA and PKC $\alpha$, and PKC $\alpha$ mediates RhoA inhibition. 


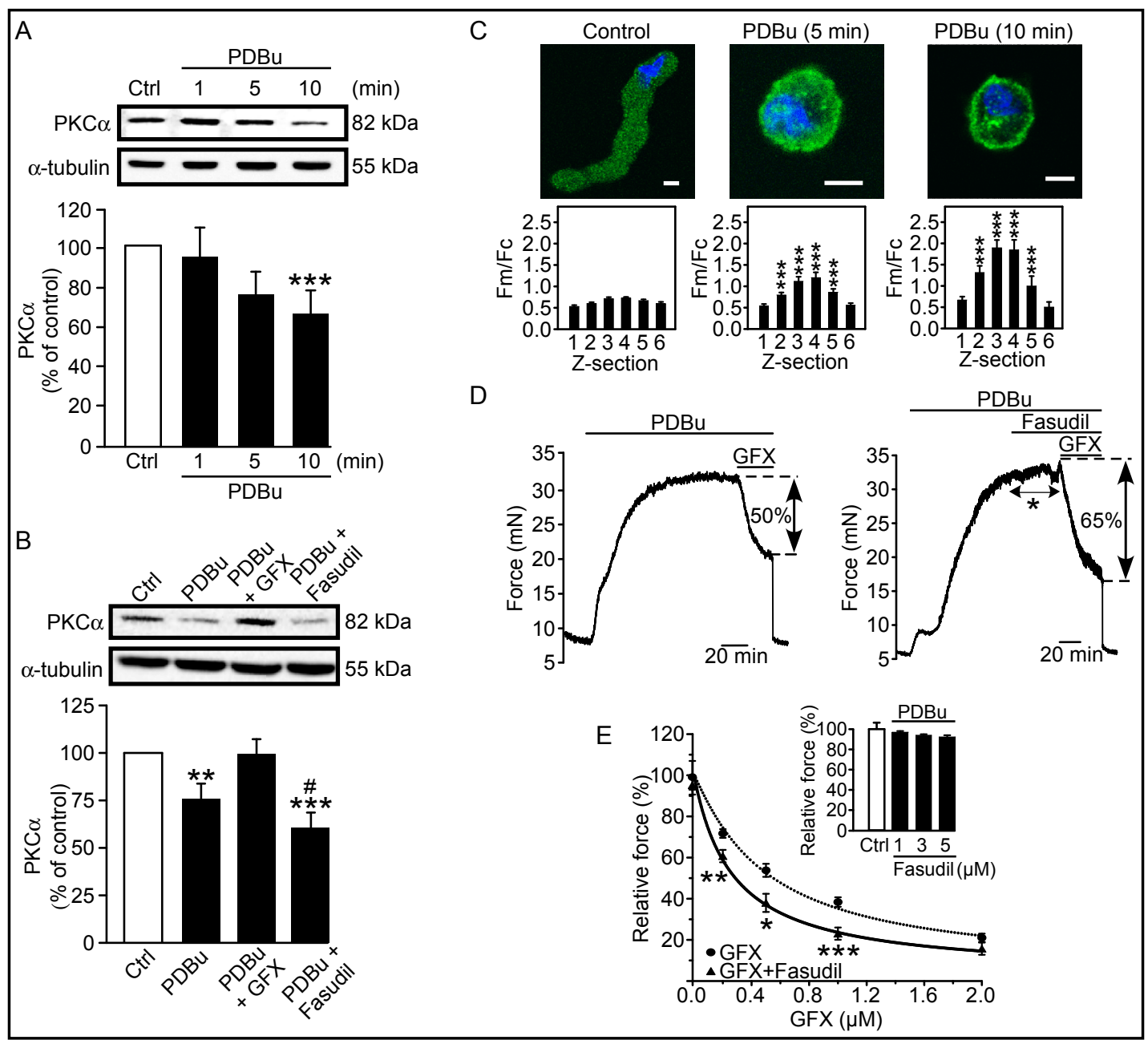

Fig. 6. Analysis of the role of $\mathrm{PKC} \alpha$ and RhoA/ROCK in PDBu-treated rat femoral arterial rings. (A) Representative immunoblot (top) and analysis (bottom) showing PKC $\alpha$ levels in cytosolic fractions during stimulation with PDBu $(0.2 \mu \mathrm{M})(\mathrm{n}=5) .{ }^{* * *} \mathrm{P}<0.005$. (B) Representative immunoblot (top) and analysis (bottom) of the effects of GFX $(0.5 \mu \mathrm{M})$ and fasudil $(1 \mu \mathrm{M})$ on PKC $\alpha$ cytosolic levels $(\mathrm{n}=6) .{ }^{* *} \mathrm{P}<0.01,{ }^{* * *} \mathrm{P}<0.005$, vs. control; " $\mathrm{P}<0.05$ vs. PDBu plus GFX. (C, top panels) PKC $\alpha$ distribution (PKC $\alpha$, green; cell nucleus, blue) in a representative femoral smooth muscle cell under resting conditions (control) and after stimulation with PDBu $(0.2 \mu \mathrm{M})$ for 5 and $10 \mathrm{~min}$. Scale bar represents $8 \mu \mathrm{m}$. (C, bottom panels) Fluorescence intensity analyses (averaged peripheral (Fm):cytosolic ( $\mathrm{Fc}$ ), $\mathrm{Fm} / \mathrm{Fc}$ ) for different $\mathrm{Z}$ sections in control solution and at different times (5 and $10 \mathrm{~min}$ ) in PDBu $(\mathrm{n}=9) .{ }^{* * *} \mathrm{P}<0.005$ vs. Z-section 1 . (D) Isometric force developed in response to PDBu $(0.2 \mu \mathrm{M})$ in the presence of the PKC $\alpha$ inhibitor GFX $(0.5 \mu \mathrm{M})$ (left) or GFX plus fasudil (1 $\mu \mathrm{M})$ (right). The asterisk illustrates the lack of effect of fasudil. (E) Dose-response curves of the cumulative vasorelaxant effects of GFX alone $(\boldsymbol{O})(n=8)$ or in the presence of $1 \mu$ M fasudil $(\boldsymbol{\Delta})(n=6)$. The inset shows the lack of effect of fasudil (1-5 $\mu \mathrm{M})$ on the PDBu-induced contraction. Dose-response curves were fitted to a logistic equation using nonlinear regression analysis tools provided in SigmaPlot software. Statistical significance was calculated by one-way ANOVA or Kruskal-Wallis test followed by either Student-NewmanKeuls t-test, Tukey, or MannWhitney U test, where appropriate. ${ }^{*} \mathrm{P}<0.05$, ${ }^{* *} \mathrm{P}<0.01,{ }^{* * *} \mathrm{P}<0.005$. 


\section{Cellular Physiology Cell Physiol Biochem 2019;52:76-93

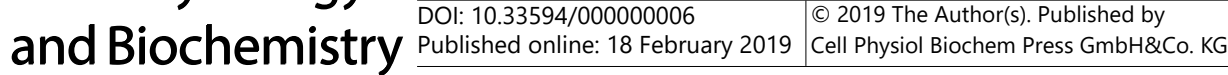 \\ González-Montelongo et al.: Functional Role of PKC $\alpha$-Induced RhoA Inhibition}

In this way, application of PKC $\alpha$ inhibitors reduces the negative effect of PKC $\alpha$ on RhoA, potentiating RhoA/ROCK function and, thus, the effectiveness of ROCK inhibitors.

Phorbol Esters Negatively Regulate RhoA Activity: Synergistic Vasorelaxant Effect of ROCK and PKC Inhibitors on PDBu-induced Sustained Contraction

As depolarization is a stimulus that activates both PKC $\alpha$ and RhoA, we sought to determine if the PKC $\alpha$-induced RhoA inhibition and the synergistic effect of PKC and ROCK inhibitors is also observed in arterial rings pharmacologically precontracted with $\mathrm{PDBu}$, which mainly activates PKC $\alpha$. Application of PDBu $(0.2 \mu \mathrm{M})$ elicited a decrease in PKC $\alpha$ cytosolic levels measured by western blot analysis (Fig. 6A), indicating PKC $\alpha$ activation. As expected, the effect of PDBu was totally reversed when arteries were pretreated with GFX for 30 min (Fig. 6B, see also Fig. 2A). However, in contrast to what was observed during depolarization, the $\mathrm{PDBu}$-elicited translocation of PKC $\alpha$ was not reversed by fasudil, suggesting that ROCK is not involved in the activation of PKC $\alpha$ produced by PDBu. These results were confirmed by immunoassays. Treatment with $0.2 \mu \mathrm{M}$ PDBu for 5 and 10 min produced VSMCs contraction and translocated PKC $\alpha$ to the cellular periphery (Fig. 6C). Similarly, to depolarization (see Fig. 4D), PDBu-induced isometric force was synergistically reduced by simultaneous application of PKC and ROCK inhibitors $\left(\mathrm{IC}_{50}=0.55 \mu \mathrm{M}\right.$ GFX, $\mathrm{IC}_{50}=0.28 \mu \mathrm{M} \mathrm{GFX}+$ fasudil) (Fig. $6 \mathrm{D}$ and $\mathrm{E}$ ). This effect was also observed when basilar arterial rings were treated with PDBu $(0.1 \mu \mathrm{M})$ or PMA $(0.2 \mu \mathrm{M})$. Fasudil $(1-3 \mu \mathrm{M})$ did not produce significant effects on PDBU- or PMA induced contraction $(0 \pm 8 \%$ relaxation for PDBu $+1 \mu \mathrm{M}$ Fasudil; $10 \pm 7 \%$ relaxation for PDBu $+3 \mu \mathrm{M}$ Fasudil; $-0.03 \pm 13 \%$ relaxation for PMA $+1 \mu \mathrm{M}$ Fasudil; $\mathrm{n}=5$ ), whereas Fasudil + GFX $(0.2 \mu \mathrm{M})$ induced a marked arterial vasorelaxation $(88 \pm 5 \%$ for PDBu $+3 \mu \mathrm{M}$ Fasudil; $80 \pm 11 \%$ relaxation for PMA $+1 \mu$ M Fasudil; $n=4$ ) (data not shown). To analyze the role of RhoA in this response, arteries were treated with PDBu for 10 min and RhoA cellular distribution and activity were analyzed. Interestingly, in $\mathrm{PDBu}$-treated arteries RhoA protein level increased in the cytosol (Fig. 7A) and decreased in the plasma membrane (Fig. 7B), suggesting that this PKC activator downregulates RhoA activity. As expected, an opposite effect was observed when arteries were treated with U46619 (Fig. 7, A and B). These results were confirmed using the G-LISA assay, showing that PDBu significantly reduced, whereas U46619 increased, RhoA activity (Fig. 7C). Interestingly, GFX, that inhibited PKC and potentiated RhoA activity in depolarized arteries (see Fig. 2, A and C), also blocked the decrease in RhoA activity produced by PDBu (Fig. 7D). To examine whether activation of PKC really inhibits the RhoA/ROCK pathway, we studied the phosphorylation level of MYPT1, a good reporter of ROCK activity. As expected, PDBu reduced phosphorylation of MYPT1 at Thr850 (Fig. 7E). A second MYPT1 band of $80 \mathrm{kDa}$, also reported by other laboratories [30], showing the same response pattern was also detected (not shown). As it has been previously reported, in a VSMCs line (A7r5), that PKC $\alpha$ negatively regulates RhoA activity through the Src-dependent tyrosine phosphorylation/activation of p190RhoGAP [10], we performed experiments to test whether this signaling pathway could be involved in our observations. PP2 $(5 \mu \mathrm{M})$, an inhibitor of the Src family of kinases, did not mimic the effects of GFX on RhoA activity in PDBu $(0.2 \mu \mathrm{M})$ treated arteries (RhoA activity reduction for PDBu $=44 \pm 0.05 \%$, and $\mathrm{PDBu}+\mathrm{PP} 2=44 \pm 0.10 \% ; \mathrm{n}=3$ ) (data not shown), suggesting that the downregulation of RhoA activity described in the present report is not mediated by p190RhoGAP. Taken together, these data indicate that depolarization or phorbol esters activate PKC $\alpha$ which negatively regulate RhoA/ROCK function. The presence of PKC $\alpha$ inhibitors facilitates RhoA/ ROCK function and increases the vasorelaxant effect of ROCK inhibitors. 


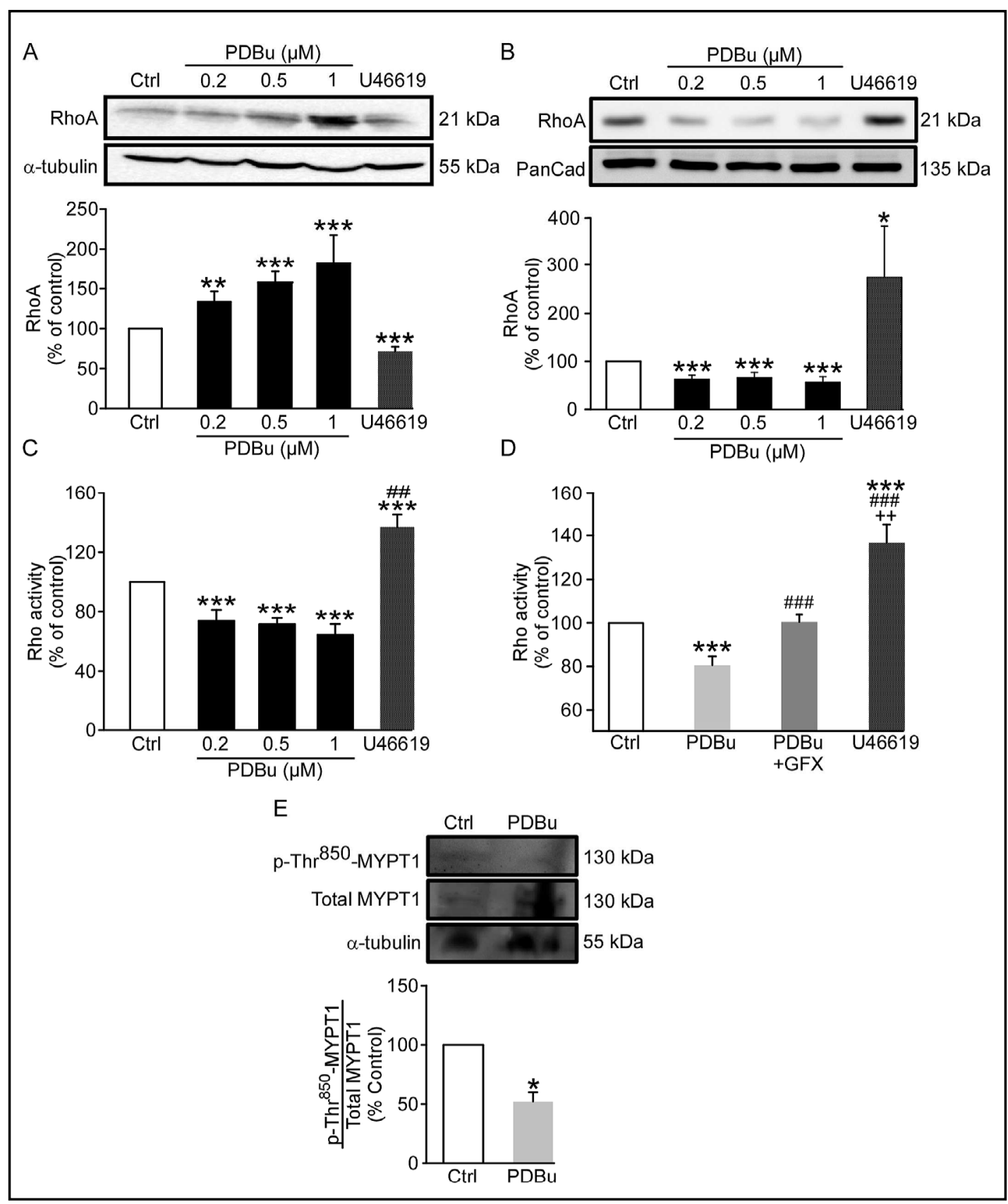

Fig. 7. Analysis of the role of RhoA in PDBu-treated femoral arterial rings. Representative immunoblot and densitometric analysis showing RhoA levels in cytosolic fractions (A) or membrane (B) obtained from arteries exposed to PDBu. $(\mathrm{n}=10)$. ${ }^{*} \mathrm{P}<0.5,{ }^{* *} \mathrm{P}<0.01,{ }^{* * *} \mathrm{P}<0.005$ vs. control. (C) RhoA activity measured at $10 \mathrm{~min}$ in $\mathrm{PDBu}(\mathrm{n}=5) .{ }^{* * *} \mathrm{P}<0.005$ vs. control, ${ }^{\# \#} \mathrm{P}<0.01$ vs. PDBu. (D) RhoA activity in arterial segments incubated in different conditions. GFX $(0.5 \mu \mathrm{M})$ was applied $30 \mathrm{~min}$ before PDBu. PDBu $(0.2 \mu \mathrm{M})$ and $\mathrm{U} 46619(1 \mu \mathrm{M})$ were applied for $10 \mathrm{~min}(\mathrm{n}=7)$. Statistical significance was calculated by one-way ANOVA or Kruskal-Wallis test followed by either Student-Newman-Keuls t-test, Tukey, or MannWhitney U test, where appropriate. ${ }^{* * *} \mathrm{P}<0.005$ vs. control, ${ }^{\# \#} \mathrm{P}<0.005$ vs. $\mathrm{PDBu},{ }^{++} \mathrm{P}<0.01$ vs. $\mathrm{PDBu}+\mathrm{GFX}$. (E) Immunoblot shows p-Thr850-MYPT1 and total MYPT1 from arteries treated with vehicle (ctrl) and PDBu (0.2 $\mu$ M) (top). Densitometric analysis of data was normalized to control (bottom). Comparison between treatments from the same animals was assessed by Friedman test followed by either Wilcoxon signed-rank test $(n=6)$. $* \mathrm{P}<0.05$. 


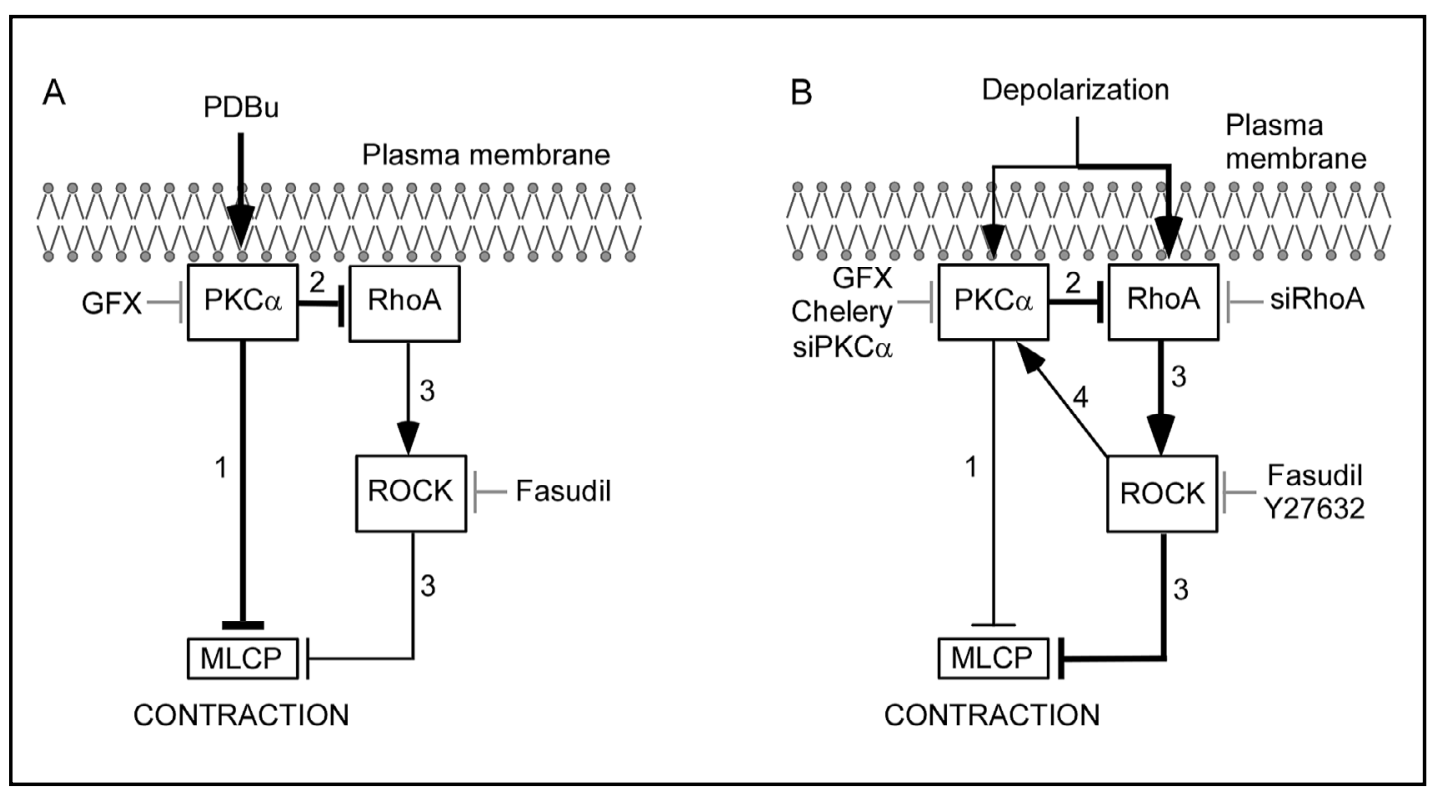

Fig. 8. Model illustrating the crosstalk between PKC $\alpha$ and RhoA/ROCK. (A) PDBu-induced contraction could be mediated by PKC $\alpha$ activation and MLCP inhibition (pathway 1). Pathway 2 indicates the inhibitory effect of PKC $\alpha$ on RhoA/ROCK. (B) In depolarized arteries, both RhoA/ROCK (pathway 3) and PKC $\alpha$ (pathway 1 ), are activated leading to MLCP inhibition and contraction. RhoA/ROCK function, that is important in depolarization-induced contraction, is negatively regulated by $\mathrm{PKC} \alpha$ (pathway 2). Activation of ROCK exerts a negative feedback on RhoA activity through pathways 4 and 2.

\section{Discussion}

To the best of our knowledge, our data reveal, for the first time, a new interplay between $\mathrm{PKC} \alpha$ and RhoA/ROCK pathway in freshly isolated arterial rings. This interaction could have important physiological implications on arterial contraction.

\section{PKC $\alpha$ Reduces RhoA Activity in Depolarized or PDBu-treated Arteries}

Here, we show that depolarization recruits PKC $\alpha$ and RhoA to the plasma membrane, where they colocalize and coimmunoprecipitate, indicating that both proteins interact. GFX, an inhibitor of $\alpha, \beta, \delta, \gamma$ and $\varepsilon$ PKC isoenzymes [28], reduced PKC $\alpha$ translocation and potentiated RhoA activity, suggesting a new inhibitory effect of PKC $\alpha$ on RhoA in depolarized VSMCs. The PKC $\alpha$ activation shown in this report could be a consequence of depolarizationinduced triggering of a metabotropic signaling pathway that eventually activates PKC, as previously reported by our group and others [23, 31, 32]. In depolarized arteries fasudil abolished PKC $\alpha$ translocation, suggesting that ROCK is involved in PKC $\alpha$ activation. This result is not surprising, since agonist-induced activation of RhoA/ROCK eventually leads to PKC $\alpha$ activation [9], and we have previously reported that depolarization activates RhoA/ ROCK pathway [15]. In agreement with these results we show that PDBu, besides inducing PKC $\alpha$ translocation and activation, also increases cytosolic RhoA and reduces its activity, what could explain, as opposed to depolarization, the lack of effect of fasudil on PKC $\alpha$ traslocation. In PDBu and depolarized arteries GFX increases RhoA activity, suggesting that both stimuli inhibit RhoA through PKC $\alpha$. These results are consistent with a previous report in a VSMCs line (A7r5) showing PKC-dependent down-regulation of Rho activity in TPA treated cells [10]. On the contrary, PDBu induces RhoA/ROCK activation in human internal anal sphincter smooth muscle cells [33]. So, the effect of PKC $\alpha$ on RhoA may depend on the cell type studied and stimulus used. In PDBu-treated arteries, where PKC $\alpha$ and PKC $\eta$ isoenzymes are activated, the effect of GFX could be mediated by an effective inhibition of PKC $\alpha$, as PKC $\eta$ is not affected 


\section{Cellular Physiology Cell Physiol Biochem 2019;52:76-93

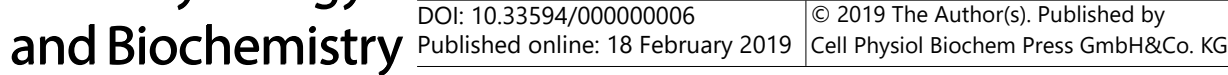 \\ González-Montelongo et al.: Functional Role of PKC $\alpha$-Induced RhoA Inhibition}

by GFX. However, in depolarized arteries we cannot rule out the participation of PKC $\beta$ and $\mathrm{PKC} \delta$, as these isoenzymes are also activated in addition to PKC $\alpha$.

Although it is known that cAMP and cyclic GMP-dependent kinases (PKA and PKG, respectively) inhibit RhoA-dependent functions in agonist treated VSMCs [34], the new crosstalk between PKC $\alpha$ and RhoA/ROCK in depolarized VSMCs described in this report represents a newly identified mechanism involved in the regulation of $\mathrm{Ca}^{2+}$ sensitization in VSMCs. Our results do not distinguish between the possibility that association of PKC $\alpha$ with RhoA can occur directly or whether it is mediated through a molecular link. Evidences for a direct protein-protein interaction between certain PKC isoenzymes and Rho GTPases that results in RhoA activation have been described previously [35]. On the other hand, RhoA could also associate with other molecules forming a complex. Consistent with this idea, it has been described that HSP27 can be a potential molecular link between RhoA and PKC $\alpha$ [36]. Further experiments are necessary to analyze the molecular basis of the interaction between PKC $\alpha$ and RhoA in VSMCs.

\section{Physiological Significance of the Present Findings}

Our data support a working model including a new crosstalk between PKC $\alpha$ and RhoA/ ROCK with an important physiological role on sustained arterial contraction (Fig. 8). Fig. $8 \mathrm{~A}$ shows that PDBu-induced contraction could be mediated by PKC $\alpha$ activation and MLCP inhibition (pathway 1). As PKC $\alpha$ also reduced RhoA/ROCK activity (pathway 2), arterial contraction induced by RhoA/ROCK (pathway 3 ) is not important in this process. It could explain, the lack of effect of ROCK inhibitors on contraction in phorbol-ester treated arteries described here (Fig. 6D and E) and reported by other laboratories [37]. In depolarized arteries, both RhoA/ROCKand PKC $\alpha$ are activated, leading to MLCP inhibition and contraction (pathways 3 and 1, respectively). Our data show that RhoA/ROCK is the most important pathway under this stimulus and that their function is negatively regulated by PKC $\alpha$ (pathway 2). In vitro experiments indicate that GFX increases RhoA activity (Fig. 2C), which should increase contraction through pathway 3. However, functional experiments show that GFX has no effect on depolarization-induced contraction (Fig. 4B). This could reflect that potentiation of contraction through pathway 3 is counteracted by the vasorelaxation induced by the inhibition of pathway 1 and the negative feedback of ROCK on RhoA through pathway 4 and 2.

The synergistic vasorelaxant effect of GFX and fasudil in depolarized and PDBu-treated arteries could be a consequence of the fact that the presence of PKC $\alpha$ inhibitors facilitates RhoA/ROCK function and increases the vasorelaxant effect of fasudil. In contrast, in depolarized arteries, the presence of PDBu, that activates PKC $\alpha$ and reduces RhoA activity, suppressed the vasorelaxant effect of fasudil (Fig. 5B). In conclusion, although further studies are needed to determine the role of $\mathrm{Ca}^{2+}$ sensitization in vascular pathophysiology, the combined use of ROCK and PKC $\alpha$ inhibitors might be an attractive therapeutic strategy in the treatment of the arterial vasospasm present in some cardiovascular diseases [38, 39].

\section{Acknowledgements}

This work was supported by the "Red de Investigación Cardiovascular, RIC, RD12/0042/0041" of the Instituto de Salud Carlos III and by Ministerio de Economía y Competitividad and FEDER (SAF2013-46806-R and SAF2017-89474-R). We thank Dr. Konstantin Levitsky (Instituto de Biomedicina de Sevilla) for technical help with the confocal microscopy. The authors acknowledge support from Supercomputing and Bioinformatics Center at Malaga University to carry out the studies in IPA. 


\section{Cellular Physiology Cell Physiol Biochem 2019;52:76-93 \begin{tabular}{l|l|l}
\cline { 2 - 3 } DOl: 10.33594/000000006 & (c) 2019 The Author(s). Published by
\end{tabular} and Biochemistry Published online: 18 February 2019 Cell Physiol Biochem Press GmbH\&Co. KG

\section{Disclosure Statement}

article.

The authors declare that they have no conflicts of interest with the contents of this

\section{References}

1 Somlyo AP, Somlyo AV: $\mathrm{Ca}^{2+}$ sensitivity of smooth muscle and nonmuscle myosin II: modulated by G proteins, kinases, and myosin phosphatase. Physiol Rev 2003;83:1325-1358. Berridge MJ: Smooth muscle cell calcium activation mechanisms. J Physiol 2008;586:5047-5061. Newton AC: Protein kinase C: Structure, function, and regulation. J Biol Chem 1995;270:28495-28498. Davies SP, Reddy H, Caivano M, Cohen P: Specificity and mechanism of action of some commonly used protein kinase inhibitors. Biochem J 2000;351:95-105.

- 5 Boulter E, Estrach S, Garcia-Mata R, Féral CC: Off the beaten paths: alternative and crosstalk regulation of Rho GTPases. FASEB J 2012;26:469-479.

- 6 Masuo M, Reardon S, Ikebe M, Kitazawa T: A novel mechanism for the $\mathrm{Ca}^{2+}$-sensitizing effect of protein kinase $\mathrm{C}$ on vascular smooth muscle: inhibition of myosin light chain phosphatase. J Gen Physiol 1994;104:265-286.

7 Taggart MJ, Lee YH, Morgan KG: Cellular redistribution of PKC $\alpha$, RhoA, and ROK $\alpha$ following smooth muscle agonist stimulation. Exp Cell Res 1999;25:92-101.

- 8 Gohla A, Schultz G, Offermanns S: Role for $\mathrm{G}_{12} / \mathrm{G}_{13}$ in agonist-induced vascular smooth muscle cell contraction. Circ Res 2000;87:221-227.

- 9 Murthy KS, Zhou H, Grider JR, Makhlouf GM: Sequential activation of heterotrimeric and monomeric G proteins mediates PLD activity in smooth muscle. Am J Physiol Gastrointest Liver Physiol 2001;280:G381-G388.

10 Brandt D, Gimona M, Hillmann M, Haller H, Mischak H: Protein kinase C induces actin reorganization via a Src- and Rho-dependent pathway. J Biol Chem 2002;277:20903-20910.

- 11 Kandabashi T, Shimokawa H, Miyata K, Kunihiro I, Eto Y, Morishige K, Matsumoto Y, Obara K, Nakayama K, Takahashi S, Takeshita A: Evidence for protein kinase C-mediated activation of Rho-kinase in a porcine model of coronary artery spasm. Arterioscler Thromb Vasc Biol 2003;23:2209-2214.

12 Mita M, Yanagihara H, Hishinuma S, Saito M, Walsh MP: Membrane depolarization-induced contraction of rat caudal arterial smooth muscle involves Rho-associated kinase. Biochem J 2002;364:431-440.

13 Sakurada S, Takuwa N, Sugimoto N, Wang Y, Seto M, Sasaki Y, Takuwa Y: $\mathrm{Ca}^{2+}$-dependent activation of Rho and Rho kinase in membrane depolarization-induced and receptor stimulation-induced vascular smooth muscle contraction. Circ Res 2003;93:548-556.

14 Ratz PH, Berg KM, Urban NH, Miner AS: Regulation of smooth muscle calcium sensitivity: KCl as a calciumsensitizing stimulus. Am J Physiol Cell Physiol 2005;288:C769-C783.

15 Fernández-Tenorio M, Porras-González C, Castellano A, del Valle-Rodríguez A, López-Barneo J, Ureña J: Metabotropic regulation of RhoA/Rho-associated kinase by L-type $\mathrm{Ca}^{2+}$ channels: new mechanism for depolarization-evoked mammalian arterial contraction. Circ Res 2011;108:1348-1357.

- 16 Porras-González C, González-Rodríguez P, Calderón-Sánchez E, López-Barneo J, Ureña J: Low-dose combination of Rho kinase and L-type $\mathrm{Ca}^{2+}$ channel antagonists for selective inhibition of depolarizationinduced sustained arterial contraction. Eur J Pharmacol 2014;5:130-138.

- 17 Ohanian V, Ohanian J, Shaw L, Scarth S, Parker PJ, Heagerty AM: Identification of protein kinase C isoforms in rat mesenteric small arteries and their possible role in agonist-induced contraction. Circ Res 1996;78:806-812.

- 18 Maasch C, Wagner S, Lindschau C, Alexander G, Buchner K, Gollasch M, Luft FC, Haller H: Protein kinase C $\alpha$ targeting is regulated by temporal and spatial changes in intracellular free calcium concentration $\left[\mathrm{Ca}^{2+}\right]_{\mathrm{i}^{*}}$ FASEB J 2000;14:1653-1663.

19 Harder DR, Dernbach P, Waters A: Possible cellular mechanism for cerebral vasospasm after experimental subarachnoid hemorrhage in the dog. J Clin Invest 1987;80:875-880.

20 Laher I, Zhang JH: Protein kinase C and cerebral vasospasm. J Cereb Blood Flow Metab 2001;21:887-906. 


\section{Cellular Physiology Cell Physiol Biochem 2019;52:76-93 \begin{tabular}{l|l|l}
\cline { 2 - 3 } DOI: 10.33594/000000006 & (c) 2019 The Author(s). Published by
\end{tabular} and Biochemistry Published online: 18 February 2019 Cell Physiol Biochem Press GmbH\&Co. KG

21 Pesic A, Madden JA, Pesic M, Rusch NJ: High blood pressure upregulates arterial L-type $\mathrm{Ca}^{2+}$ channels: is membrane depolarization the signal? Circ Res 2004;94:e97-e104.

- 22 Nystoriak MA, O'Connor KP, Sonkusare SK, Brayden JE, Nelson MT, Wellman GC: Fundamental increase in pressure-dependent constriction of brain parenchymal arterioles from subarachnoid hemorrhage model rats due to membrane depolarization. Am J Physiol Heart Circ Physiol 2011;300:H803-H812.

- 23 Del Valle-Rodríguez A, López-Barneo J, Ureña J: $\mathrm{Ca}^{2+}$ channel-sarcoplasmic reticulum coupling: a mechanism of arterial myocyte contraction without $\mathrm{Ca}^{2+}$ influx. EMBO J 2003;22:4337-4345.

24 GSL Biotech: SnapGene® software. URL: www.snapgene.com.

- 25 Kim SC, Chen Y, Mirza S, Xu Y, Lee J, Liu P, Zhao Y: A clean, more efficient method for in-solution digestion of protein mixtures without detergent or urea. J Proteome Res 2006;5:3446-3452.

26 Qiaqen: Ingenuity Pathway Analysis software. URL: www.qiagen.com/ingenuity.

27 Yeon DS, Kim JS, Ahn DS, Kwon SC, Kang BS, Morgan KG, Lee YH: Role of protein kinase C- or RhoAinduced $\mathrm{Ca}^{2+}$ sensitization in stretch-induced myogenic tone. Cardiovasc Res 2002;53:431-438.

28 Toullec D, Pianetti P, Coste H, Bellevergue P, Grand-Perret T, Ajakane M, Baudet V, Boissin P, Boursier E, Loriolle F, Duhamel L, Charon D, Kirilovsky J: The bisindolylmaleimide GF 109203X is a potent and selective inhibitor of protein kinase C. J Biol Chem 1991;266:15771-15781.

29 Ming XF, Viswambharan H, Barandier C, Ruffieux J, Kaibuchi K, Rusconi S, Yang Z: Rho GTPase/Rho kinase negatively regulates endothelial nitric oxide synthase phosphorylation through the inhibition of protein kinase B/Akt in human endothelial cells. Mol Cell Biol 2002;22:8467-8477.

- 30 Xu EZ, Kantores C, Ivanovska J, Engelberts D, Kavanagh BP, McNamara PJ, Jankov RP: Rescue treatment with a Rho-kinase inhibitor normalizes right ventricular function and reverses remodeling in juvenile rats with chronic pulmonary hypertension. Am J Physiol Heart Circ Physiol 2010;299:H1854-H1864.

- 31 Ganitkevich VYa, Isenberg G: Membrane potential modulates inositol 1, 4,5-trisphosphate- mediated Ca ${ }^{2+}$ transients in guinea-pig coronary myocytes. J Physiol 1993;470:35-44.

32 Yamamura H, Ohya S, Muraki K, Imaizumi Y: Involvement of inositol 1, 4,5-trisphosphate formation in the voltage-dependent regulation of the $\mathrm{Ca}^{2+}$ concentration in porcine coronary arterial smooth muscle cells. J Pharmacol Exp Ther 2012;342:486-496.

33 Singh J, Maxwell PJ 4th, Rattan S: Immunocytochemical evidence for PDBu-induced activation of RhoA/ ROCK in human internal anal sphincter smooth muscle cells. Am J Physiol Gastrointest Liver Physiol. 2011;301:G317-G325.

34 Murthy KS, Zhou H, Grider JR, Makhlouf GM: Inhibition of sustained smooth muscle contraction by PKA and PKG preferentially mediated by phosphorylation of RhoA. Am J Physiol Gastrointest Liver Physiol 2003;284:G1006-G1016.

- 35 Pang H, Bitar KN: Direct association of RhoA with specific domains of PKC-alpha. Am J Physiol Cell Physiol 2005;289:C982-C993.

- 36 Patil SB, Pawar MD, Bitar KN: Phosphorylated HSP27 essential for acetylcholine-induced association of RhoA with PKCalpha. Am J Physiol Gastrointest Liver Physiol 2004;286:G635-G644.

- 37 Fu X, Gong MC, Jia T, Somlyo AV, Somlyo AP: The effects of the Rho-kinase inhibitor Y-27632 on arachidonic acid-, GTPgammaS-, and phorbol ester-induced $\mathrm{Ca}^{2+}$-sensitization of smooth muscle. FEBS Lett 1998;440:183-187.

38 Uehata M, Ishizaki T, Satoh H, Ono T, Kawahara T, Morishita T, Tamakawa H, Yamagami K, Inui J, Maekawa M, Narumiya S: Calcium sensitization of smooth muscle mediated by a Rho-associated protein kinase in hypertension. Nature 1997;389:990-994.

39 Zhao J, Zhou D, Guo J, Ren Z, Zhou L, Wang S, Zhang Y, Xu B, Zhao K, Wang R, Mao Y, Xu B, Zhang X: Fasudil Aneurysmal Subarachnoid Hemorrhage Study Group: Efficacy and safety of fasudil in patients with subarachnoid hemorrhage: final results of a randomized trial of fasudil versus nimodipine. Neurol Med Chir 2011;51:679-683. 